\title{
Public Lecture: Parks and Recreation converging issues in urban cultural planning and national and provincial parks
}

In North America the creation of national parks was influenced by a belief in the spiritual and moral benefit of access to pristine nature, an idea also influencing the creation of parks and green spaces in cities. To meet this ideal national park lands have been expropriated from both aboriginal and settler peoples; hunting, agriculture, forestry, and mining have been managed, tolerated or banned; tourist access has been pitted against pristine environments; archeology and guiding have been professionalized; co-management has been initiated between First Nations and parks authorities, and the target visitor has been calculated and recalculated from elite leisure classes to elite adventurers to (recently) new immigrants with a need to be educated in the use of parks.

There are many similarities between these issues in national parks, urban parks and green space management. With examples drawn from Vancouver, BC parks use policy, and Canada's national parks, this paper will suggest the potential of revisiting an urban-rural distinction that has led to a policy blind spot.

\section{All Welcome}

Thursday, April 9, 2015

12:00pm - 2:00pm | Room HC

2270

\section{Harbour Centre}

Simon Fraser University

515 W. Hastings St.

Unceded Coast Salish Territories/

Vancouver
Professor Alison Beale is a faculty member in the School of Communication at Simon Fraser University and a founding member of the CPCC. Her research on Cultural Policy has included urban cultural policy and planning, the history of cultural diversity and feminist political economy applied to international cultural policy issues, and the dilemmas shared by national and provincial parks and World Heritage sites, and towns and cities. 